\title{
Correction to: Using geophysical logs to identify Milankovitch cycles and to calculate net primary productivity (NPP) of the Late Permian coals, western Guizhou, China
}

Zhi-Ming Yan ${ }^{1}$, Long-Yi Shao ${ }^{1 *}$, David Large ${ }^{2}$, Hao Wang ${ }^{1}$ and Baruch Spiro ${ }^{3}$

Correction to: Journal of Palaeogeography https://doi.org/10.1186/s42501-018-0017-z

After publication of this article (Yan et al. 2019), it is noticed the article contains some error:

'※P3-2' in 'Discussion' section (on page 11 of the PDF) need to be corrected to 'aP3-2'.

The original article has been updated accordingly. We apologize for the inconvenience caused.

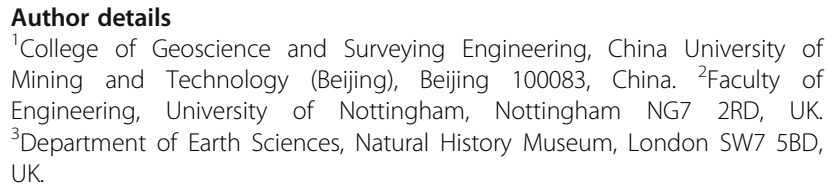

Received: 16 January 2019 Accepted: 16 January 2019

Published online: 30 January 2019

\section{Reference}

Yan, et al. 2019. Using geophysical logs to identify Milankovitch cycles and to calculate net primary productivity (NPP) of the late Permian coals, western Guizhou, China. Journal of Palaeogeography 8: 2 https://doi.org/10.1186/ s42501-018-0017-z.

\footnotetext{
* Correspondence: shaol@cumtb.edu.cn

The original article can be found online at https://doi.org/10.1186/s42501018-0017-z

${ }^{1}$ College of Geoscience and Surveying Engineering, China University of

Mining and Technology (Beijing), Beijing 100083, China

Full list of author information is available at the end of the article
} 